\title{
Study on Hydrogenation Performance of Oil-Soluble Molybdenum Catalyst in Coal-Oil Co-Processing
}

\section{Guangyao Wang ( $\nabla$ wgyaoo@163.com )}

China Coal Research Institute Corporation Ltd. https://orcid.org/0000-0002-7265-8050

\section{Xiqian Wang}

China Coal Technology and Engineering Group Corp China Coal Research Institute

\section{Yuan Zhao}

China Coal Technology and Engineering Group Corp China Coal Research Institute

\section{Research}

Keywords: coal-oil co-processing, oil-soluble catalyst, molybdenum catalyst, hydrogenation performance, model reactants

Posted Date: January 6th, 2022

DOI: https://doi.org/10.21203/rs.3.rs-1216417/v1

License: (c) (1) This work is licensed under a Creative Commons Attribution 4.0 International License. Read Full License 


\section{Abstract}

An oil-soluble molybdenum catalyst was synthesized by a simple and novel method and studied for hydrogenation in coal-oil co-processing. The catalyst was characterized by infrared spectrum (IR), thermogravimetry (TG), X-ray diffraction (XRD) and X-ray photoelectron spectroscopy (XPS). The morphology and crystal structure of catalyst was characterized with scanning electron microscope (SEM) and high resolution transmission electron microscopy (HRTEM). The catalyst can be considered as a precursor that can be converted into active MoS2 components through thermal decomposition and sulfidation. The hydrogenation experiment was carried out by the model reactants of tetradecane and 2methylnaphthalene with a change of reaction $\left(405^{\circ} \mathrm{C}-445^{\circ} \mathrm{C}\right)$ temperature and concentrations of molybdenum catalyst (Mo conc. 0.6-10 mg/g), and results showed that the delightly hydrogenation function of catalyst is to improve the saturation of aromatic ring. The most abundant stacking numbers of decomposed catalyst were 2 and 3 , accounting for $53 \%$ of all catalyst microcrystalline units. The rapid hydrogenation stage and the significant decrease of feed heavy fraction in co-processing experiment provided the evidence that the hydrogenation performance of the synthesized catalyst is remarkable in coal-oil co-processing.

\section{Introduction}

Considering the resource characteristics, the utilization of coal has propelled the progress of economic and social development in China(Hu et al. 2019). Thus, it is crucial that, in the short to medium term, the energy structure mainly based on fossil fuels will not change. All the time coal chemical industry(Bae et al. 2012) is the important complementary strength of the petrochemical industry. The trend of development of advanced processes and technologies for the effective upgrading of fossil fuels into chemicals and specialty oil products will continue in the future(Han et al. 2017). Coal-oil coprocessing(Huang et al. 2016; Huang et al. 2020) is an important part of the modern coal chemical industry. Coal-oil co-processing is developed based on direct coal liquefaction technology(Vasireddy et al. 2011), which is combined with the residue hydrogenation technology. High asphaltene content and difficult conversion of heavy oil are overcome by using slurry bed reactor(Bellussi et al. 2013) in coprocessing. Through the synergistic effect of coal and heavy oil, the hydrogen utilization rate is high, which can effectively improve product quality, improve raw material conversion rate and reduce investment costs.

The first step of coal liquefaction is pyrolysis process(Liu 2010), which produces a much number of free radicals need to be hydronated(McMillen et al. 1991; Li et al. 2020). On the other hand, carbon deposition and metallic impurities can easily cause the deactivation of catalyst under operating conditions. It is widely accepted that catalyst is the key to improving the utilization rate of coal and inferior oil, which has attracted major attention of many scientists(Ikenaga et al. 1997; Bodman et al. 2002; Chianelli et al. 2009; Nikulshin et al. 2014; Li et al. 2018; Chen et al. 2019). As more and more people are keen on developing innovative hydrogenation catalysts, the pace of progress in this area is accelerating. Low-cost and environmentally friendly Fe-based particle or supported catalysts(Kuznetsov et al. 2000; Kaneko et al. 
2002; Sheng et al. 2017; Zhou et al. 2018; Xie et al. 2018; Lokhat et al. 2019; Wang et al. 2020) have been widely studied and applied in industrial installations. Unfortunately, the mediocre hydrogenation performance of iron catalyst results in general performance in coal-oil co-processing. On the contrary, Mobased catalysts(Panariti et al. 2000; Du et al. 2015; Kim 2019; Kang et al. 2019) are considered as the appropriate catalysts for hydrogenation, which has the capability to boost the demolition of heavy molecules such as asphaltenes in hydrogenation, and widely used in fixed beds, ebullated beds and slurry beds. For example, as reported by Chianelli et al(Chianelli et al. 2006), the role of molybdenite is essentially tied to its strong hydrogenation properties, which favor the removal of heteroatoms and metals, the hydrogenation of complex molecules, and the partial control of coke formation.

Mo-based catalysts can be divided into supported and unsupported types, both of which can be used in slurry bed. Studies(Liu et al. 2019) have shown that hydrocracking activity is strongly related to the quality of catalyst dispersion. The supported catalysts have low quality of dispersion and are easily to absorb coking precursor, resulting in deactivation. Oil-soluble catalysts(Nguyen et al. 2016; Xu et al. 2018; Yu et al. 2021), an important part of unsupported catalyst, can be completely dispersed in the feedstock phase, resulting in high reaction rates, with improved almost full conversion, low coke formation and high quality of liquid products. Therefore, in order to improve the catalytic performance, most efforts are focused on the development of homogeneous highly dispersant oil-soluble catalysts. Although, many synthetic methods of oil-soluble molybdenum catalysts have been proposed, most of them are applied to residue upgrading(Ortiz-Moreno et al. 2014; Nguyen et al. 2015; Wang et al. 2020), there are few investigations about the applicability of oil-soluble molybdenum catalysts in coal-oil co-processing to our knowledge.

In this work, an oil-soluble molybdenum catalyst was prepared using a simple and novel method. It can be considered as a precursor that can be converted into active $\mathrm{MoS}_{2}$ components through thermal decomposition and sulfidation. The catalytic performance of this prepared catalyst was evaluated by the hydronation reaction of model reactants in a laboratory-scale batch reactor. Moreover, the performance of catalyst in real co-processing system was investigated.

\section{Experiments}

\subsection{Catalyst preparation}

The materials required for catalyst synthesis were all purchased from Macklin. The preparation method of the catalyst is as follows: ammonium molybdate tetrahydrate $(19.6 \mathrm{~g})$ was first dissolved in $14.2 \mathrm{~g}$ of dibutylamine and $30 \mathrm{~g}$ of xylene. The mixture was heated to $65^{\circ} \mathrm{C}$ under stirring for 30 minutes. $19 \mathrm{~g}$ of carbon disulfide was dropwise added into reactor with stirring at room temperature. After that, the amaranth mixture was heated to $110^{\circ} \mathrm{C}$, refluxing for $4 \mathrm{~h}$. The product was filtered under reduced pressure, and washed with deionized water and methanol three times to obtain golden yellow rod-shaped particles. The solid was dried in at $100^{\circ} \mathrm{C}$ for $1 \mathrm{~h}$ and 120 mesh sieved.

\subsection{Catalyst characterization}


X-ray photoelectron spectroscopy (XPS) was measured by AXIS Supra ${ }^{+}$. The charge is corrected by the binding energy of polluted carbon $\mathrm{C} 1 \mathrm{~s}$, and the excitation source is $\mathrm{Al}$ target with vacuum above $5.0 \times 10^{-9}$ torr. The $\mathrm{C}, \mathrm{O}, \mathrm{N}, \mathrm{S}$ contents of the catalyst precursor were tested by elementar vario EL cube. The functional groups of catalyst were analyzed by thermo-Nicolet Nexus470 infrared spectrometer.

Thermogravimetric analysis of catalyst precursor was tested on Netzsch STA490PC with a temperature range of $10-900^{\circ} \mathrm{C}$ in the nitrogen. Gas products are characterized by Agilent 6890 gas chromatography, while liquid product was characterized by Agilent 5977B GC-MS. The solid product is catalyst, which was separated by vacuum filtration, washed with methanol and dried in oven at $100^{\circ} \mathrm{C}$ for $1 \mathrm{~h}$. X-ray powder diffraction (XRD) patterns of catalyst was on rigaku-D/max-Ultima III using Cu-Ka radiation operated with the scan rate of $10^{\circ} / \mathrm{min}$ and $2 \theta$ range of $3-90^{\circ}$. The morphology and crystal structure of catalyst was characterized with scanning electron microscope (SEM, MAIA3 TESCAN) and high resolution transmission electron microscopy (HRTEM, JEOL JEM-2100).

\subsection{Catalyst performance tests}

Hydrogenation performance of model compounds, which are tetradecane and 2-methylnaphthalene, in coal-oil co-processing with oil-soluble molybdenum catalyst was studied in a $2 \mathrm{~L}$ batch reactor. $10 \mathrm{~g}$ of 2methylnaphthalene and some of catalyst were dissolved in $100 \mathrm{~g}$ of tetradecane, and then added to the reactor in the hydrogenation experiment. The experimental conditions are a certain temperature range with an initial hydrogen pressure of $8.5 \mathrm{MPa}$, and constant temperature reacted for 1 hour with the 300 rpm stirring speed. After the reaction is over, remove the heating apparatus and cool down to room temperature naturally. In order to investigate the effect of reaction temperature on the hydrogenation performance of the catalyst, different reaction temperatures of $445,435,425,415$ and $405^{\circ} \mathrm{C}$ were selected with the $100 \mathrm{mg}$ of catalyst. In order to investigate the appropriate amount of catalyst added, the addition of catalyst content is $10,5,2.5$ or $0.6 \mathrm{mg} / \mathrm{g}$ with a reaction temperature at $415^{\circ} \mathrm{C}$.

\subsection{Coal-oil co-processing reactions}

A kind of coal from Badaowan and a coal tar from Inner Mongolia were taken as feedstock, and their properties were shown in Table 1. The study on catalytic effect of coal-oil co-processing reactions were studied in a $2 \mathrm{~L}$ batch reactor. The mass ratio of oil and coal was $3: 1$ with a condition of $200 \mathrm{mg} / \mathrm{kg}$ catalyst. The reaction temperature was $450^{\circ} \mathrm{C}$, which was selected according to the maximum thermal weight loss rate of coal, with $9.5 \mathrm{MPa}$ of hydrogen pressure at room temperature. After reacting $120 \mathrm{~min}$, the reactor was cooled by air. The products were leached and the solid products were analyzed by SEM. The liquid products were distilled to obtain the fraction of $<230^{\circ} \mathrm{C}, 230-300^{\circ} \mathrm{C}, 360-480^{\circ} \mathrm{C}$ and $>480^{\circ} \mathrm{C}$ by distillation method (ASTM D-2892). 
Table 1

Main properties of coal and oil

\begin{tabular}{|c|c|c|}
\hline Properties & Coal & Oil \\
\hline$M_{a d}(w t \%)$ & 10.34 & - \\
\hline$A_{d}(w t \%)$ & 6.05 & - \\
\hline$V_{\text {daf }}(w t \%)$ & 49.55 & - \\
\hline $\mathrm{FC}_{\text {daf }}(\mathrm{wt} \%)$ & 50.45 & - \\
\hline Density at $20^{\circ} \mathrm{C}\left(\mathrm{Kg} \cdot \mathrm{m}^{-3}\right)$ & - & 1169.0 \\
\hline Viscosity at $60^{\circ} \mathrm{C}(\mathrm{mPa} \cdot \mathrm{s})$ & - & 136 \\
\hline Ash (wt\%) & - & 0.03 \\
\hline Toluene insoluble (wt\%) & - & 3.49 \\
\hline Saturate (wt\%) & - & 0 \\
\hline Aromatics (wt\%) & - & 21.18 \\
\hline Resins (wt\%) & - & 43.04 \\
\hline Asphaltene (wt\%) & - & 32.29 \\
\hline $\mathrm{C}(\mathrm{wt} \%)$ & 76.71 & 90.98 \\
\hline$H(w t \%)$ & 5.44 & 5.71 \\
\hline $\mathrm{N}(w t \%)$ & 1.64 & 1.16 \\
\hline$S(w t \%)$ & 0.40 & 0.29 \\
\hline $\mathrm{O}(\mathrm{wt} \%)$ & 15.81 & 1.83 \\
\hline $\mathrm{H} / \mathrm{C}$ atomic ratio & 0.85 & - \\
\hline
\end{tabular}

\section{Results And Discussion}

\subsection{Characterization of catalysts}

The prepared catalyst precursor is gold needle-like solid. Observing in scanning electron microscope, the catalyst precursor is mainly a rod-shaped solid with a length of 100-400 $\mu \mathrm{m}$ and a width of 10-100 $\mu \mathrm{m}$ (Figure S1a). The rod comes from layered stacking with a smooth cross-section (Figure S1b).

The XPS data of the catalyst was analyzed and processed with accompanying software. It can be seen that the catalyst precursor mainly contains $\mathrm{C}, \mathrm{O}, \mathrm{Mo}$ and $\mathrm{S}$ elements, which are consistent with the synthesized target substance from the full spectrum of Figure 1a. In the Mo3d spectrum (Figure 1b), Mo 
mainly exists in the form of $\mathrm{Mo}^{4+}$, and contains a small amount of $\mathrm{Mo}^{6+}$ valence $\left(\mathrm{Mo}^{4+} / \mathrm{Mo}^{6+}=2.7\right)$. It is showing that part of the $\mathrm{Mo}^{6+}$ in the ammonium molybdate was not completely reduced during the reaction. In the spectrum of $S 2 p$ (Figure 1c), it can be found that $S$ exists in the form of $S^{2-}$, without $\mathrm{SO}_{3}{ }^{2-}$ or $\mathrm{SO}_{4}{ }^{2-}$. In the $01 \mathrm{~s}$ spectrum (Figure $1 \mathrm{~d}$ ), $\mathrm{O}$ element exists in the form of $\mathrm{C}-\mathrm{O}$ and $\mathrm{C}-\mathrm{O}-\mathrm{H}$ in the catalyst. Combined with the sensitivity of the XPS instrument to different elements, the content between different elements can be calculated by the peak areas. As shown in Table 2, it can be calculated that the element ratio of $\mathrm{S} / \mathrm{Mo}=2.76$, which has a high sulfur content. On the other hand, the element ratio of $(\mathrm{S}+0) / \mathrm{Mo}=4.24$, which is consistent with the target compound.

Table 2

The area of Mo, $S$ and $O$ in catalyst precursor of XPS after calibration.

\begin{tabular}{|ll|}
\hline & Integration area \\
\hline $\mathrm{Mo}^{4+}$ & 13403.40 \\
\hline $\mathrm{Mo}^{6+}$ & 4954.31 \\
\hline $\mathrm{S}$ & 50643.49 \\
\hline $\mathrm{O}$ & 27125.44 \\
\hline
\end{tabular}

The content of Mo in the catalyst precursor is an important parameter, which determines the amount of the active ingredient $\mathrm{MoS}_{2}$ in the reaction. After calcination at $700^{\circ} \mathrm{C}$ for $1 \mathrm{~h}$ in the air, the catalyst formed off white solid particles of $\mathrm{MoO}_{3}$. Table $\mathrm{S} 1$ shows the comparison of the quality of catalyst before and after calcining. It can be calculated that the content of $\mathrm{Mo}$ in the catalyst is $27.83 \%$. Based on the results of elemental analysis of $\mathrm{C}, \mathrm{H}, \mathrm{N}$ and $\mathrm{S}$ in Table 3 , the content of $\mathrm{O}$ in catalyst precursor can be calculated and summarized in Table 3.

Table 3

Elemental composition of the catalyst precursor.

\begin{tabular}{|ll|}
\hline & Experimental (wt\%) \\
\hline C & 31.14 \\
H & 5.10 \\
N & 4.17 \\
S & 26.81 \\
\hline O & 4.95 \\
\hline Mo & 27.83 \\
\hline
\end{tabular}


The catalyst precursor decomposes when temperature is going up. In Figure 2a, the catalyst precursor starts to lose weight at $280^{\circ} \mathrm{C}$, which reaching the maximum weight loss rate of $25.30 \% / \mathrm{min}$ at $301^{\circ} \mathrm{C}$, and come to be stable after $350^{\circ} \mathrm{C}$. The final weight loss rate of the catalyst is $47.48 \%$. The weight loss is the process in which the catalyst precursor is decomposed into $\mathrm{MoS}_{2}$, and it can also be known that the catalyst precursor requires a temperature higher than $350^{\circ} \mathrm{C}$ for complete sulfidation. The temperature of the model compounds hydrogenation experiment and coal-oil co-processing experiment were $>400^{\circ} \mathrm{C}$. At this temperature, most of the catalyst precursors have decomposed.

For a better understanding of the catalyst precursor, FT-IR analysis was carried out on it, and the results were presented in Figure 2b. $2956 \mathrm{~cm}^{-1}$ and $2867 \mathrm{~cm}^{-1}$ are the asymmetric stretching vibration and symmetrical stretching vibration absorption peaks of $-\mathrm{CH}_{3} ; 2929 \mathrm{~cm}^{-1}$ is the asymmetric stretching vibration absorption peak of $-\mathrm{CH}_{2}-; 1367 \mathrm{~cm}^{-1}$ and $1456 \mathrm{~cm}^{-1}$ are the flexural vibration absorption peak of $-\mathrm{CH}_{3}$ and $-\mathrm{CH}_{2}-$, respectively. $1180 \mathrm{~cm}^{-1}$ is the stretching vibration absorption peak of $\mathrm{C}-\mathrm{N} ; 1537$ $\mathrm{cm}^{-1}$ is the asymmetric stretching vibration absorption peak of $\mathrm{C}=\mathrm{S} ; 1228 \mathrm{~cm}^{-1}$ is the symmetric stretching vibration absorption peak of $\mathrm{C}=\mathrm{S} .964 \mathrm{~cm}^{-1}$ is the characteristic absorption peak of $\mathrm{Mo}=0 ; 476$ $\mathrm{cm}^{-1}$ is the characteristic absorption peak of Mo/S ring. Based on the results, it is considered that the synthesized substance is the target product.

\subsection{Catalyst performance evaluation}

There are two aspects to characterize the hydrocracking performance of the catalyst: Under the conditions of the initial hydrogen pressure of $8.5 \mathrm{MPa}$ and the reaction time of $1 \mathrm{~h}$, the effects of the reaction temperature $\left(405-445^{\circ} \mathrm{C}\right)$ and the amount of catalyst precursor $(0.6-10 \mathrm{mg} / \mathrm{g})$ on the catalytic performance were investigated respectively.

The concentration of catalyst precursor added is $10 \mathrm{mg} / \mathrm{g}$ in the reaction when adjusting the reaction temperatures. As the reaction temperature decreased, it can be seen that the content of alkanes and alkenes in the gas gradually decreases (Table S2), indicating that the lowering temperature hinders the cracking reaction of the reactants. The analysis of the liquid product found that the amount of the product from the cracking of tetradecane and 2-methylnaphthalene in the reaction decreases significantly as the reaction temperature reduced (Table S3). However, the content of 2-methylnaphthalene gradually decreased, and the amount of the two hydrogenation reaction products increased (Figure 3a). It shows that lower temperature is beneficial to the hydrogenation reaction to a certain extent and the best hydrogenation reaction temperature is $415^{\circ} \mathrm{C}$.

When investigating the amount of catalyst precursor added, the reaction temperature is fixed $a t 45^{\circ} \mathrm{C}$. From the gas composition, it can be seen that the addition of different catalyst has no obvious effect on the catalyzed gas composition (Table S4). The hydrocracking reaction remains stable when reducing the amount of catalyst, because of excess catalyst. When the amount of catalyst precursor added was decreased to $0.65 \mathrm{mg} / \mathrm{g}$, it could be found that the content of 2-methylnaphthalene increased 
significantly (Figure 3b and Table S5), which indicating that the amount of catalyst was not enough to maintain the hydrogenation reaction activity. The suitable catalyst precursor addition amount for model compounds hydrocracking experiment is $2.5 \mathrm{mg} / \mathrm{g}$. It can be proved that the function of catalyst is to improve the hydrogenation saturation of aromatic ring rather than to promote alkane cracking, which is closely related to thermal power. This conclusion is keep pace with the results of Bellussi $\mathrm{G}$ et al(Bellussi et al. 2013).

The solid product, in the model reactant experiment with $10 \mathrm{mg} / \mathrm{g}$ catalyst precursor addition at $415^{\circ} \mathrm{C}$, was firstly analyzed by XPS. In Figure 3a, the elements are still same as catalyst precursor, but the content of $\mathrm{O}$ is quite different. In Mo3d spectrum (Figure 4b), the content of $\mathrm{Mo}^{6+}$ is greatly reduced, leaving only $11.05 \%$, while $S$ is still dominated by $S^{2-}$ in S2p spectrum (Figure 4c). In Table 4, the element ratio of $\mathrm{S} / \mathrm{Mo}=1.99$, indicating that catalyst precursor forms $\mathrm{MoS}_{2}$, and do not participate in the formation of other compounds after sulfuration.

Table 4

The area of Mo and S elements in $\mathrm{MoS}_{2}$ of XPS after calibration.

\begin{tabular}{|c|c|}
\hline & Integration area \\
\hline $\mathrm{Mo}^{4+}$ & 17327.98 \\
\hline $\mathrm{Mo}^{6+}$ & 2152.66 \\
\hline S & 34499.10 \\
\hline \multicolumn{2}{|c|}{ 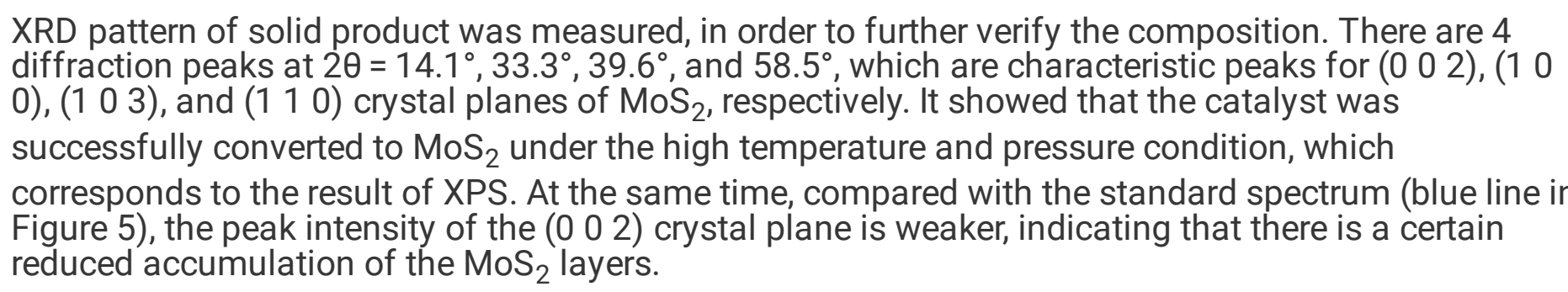 } \\
\hline
\end{tabular}

From SEM image (Figure 6a), it can be known that the black solid product forms uniform spherical particle structure about $300-700 \mathrm{~nm}$, significantly smaller than catalyst precursor. Through HRTEM image in Figure 6b, it is found that the spheres are accumulated by multiple layers of $\mathrm{MoS}_{2}$. The inter-layer spacing of $\mathrm{MoS}_{2}$ is $0.61 \mathrm{~nm}$, most of which are 2-3 layers of accumulation, corresponding to the peak shape at the XRD ( $\left.\begin{array}{lll}0 & 0 & 2\end{array}\right)$ crystal planes.

According to the statistics of randomly selecting 20 HRTEM images of $\mathrm{MoS}_{2}$, the main length of $\mathrm{MoS}_{2}$ planes are 3-10 nm, accounting for $64 \%$ of all catalysts (Figure 7a). The most abundant stacking numbers of catalysts are 2 and 3 , accounting for $53 \%$ of all catalysts (Figure $7 \mathrm{~b}$ ). It shows that the catalyst is weak stacking and good dispersibility. According to the rim-edge model(Daage 1994), the less the number of layers, the higher the catalytic performance. The in situ decomposition process ensures the 
dispersion of $\mathrm{MoS}_{2}$ mainly as fewer layers within the batch reactor. Therefore, the prepared catalyst might have good hydrogenation catalytic performance in coal-oil co-processing reaction.

In the coal-oil co-processing reactions, the temperature and pressure curves (Figure 8a) during the reaction can help us analyze the progress of the reaction. At the beginning, the high-temperature coal tar is cracked, the macromolecular structure of coal is broken, and the hydrogenation reaction is violent. As the reaction temperature is constant, the hydrogenation rate and the cracking rate enter the relative matching stage. In this stage the reaction is relatively stable and the gas generation rate and the hydrogen consumption rate reach equilibrium. After that, the hydrogenation rate is reduced, and some free radicals are not fully hydrogenated to cause polycondensation reaction. Therefore, the reaction is mainly divided into three stages: rapid hydrogenation, equilibrium cracking and reduced-rate polycondensation. From the comparison of the liquid product and coal tar fraction in the Figure $8 \mathrm{~b}$, the heavy components $>480{ }^{\circ} \mathrm{C}$ are greatly reduced after the reaction, leaving only $19.63 \%$. The proportion of light components is greatly increased, especially the distillate fraction $\left(<230^{\circ} \mathrm{C}\right)$ is $35.17 \%$, indicating that the hydrogenation effect of the catalyst is remarkable.

Coal is mainly composed of organic matter and inorganic minerals. Among them, organic matter is mainly composed of aromatic structural substances, including basic structural units composed of monoaromatics, hydrogenated aromatics, heterocyclic ring containing $\mathrm{S}, \mathrm{N}, \mathrm{O}$ and other heteroatoms, which connected to aromatic ring. The alkyl side chain and various functional groups(Taunton et al. 1981). The shape of the coal particles is irregular, and the surface is smooth and flat. The particle size of coal particles is on the order of micrometers, mostly particles smaller than $100 \mu \mathrm{m}$ (Figure S2). In Figure 9, it can be known that the particle size of the solid product after hydrogenation is much lower than that of the raw coal. The surface is loose and porous, and no obvious aggregated structure is seen. In the process of coal-oil co-processing reactions, the prepared catalyst realizes hydrogenation and light products, and the coke particle size produced is small without obvious aggregation, indicating that the prepared oil-soluble catalyst has delightful performance in coal-oil co-processing.

\section{Conclusions}

In this study, an oil-soluble molybdenum catalyst was synthesized, and the hydrogenation performance of the catalyst on the model compound was studied. The molybdenum content of prepared catalyst is $27.83 \%$, which becomes the structure of $\mathrm{MoS}_{2}$ with fewer layers after the hydrogenation reaction. In the hydrocracking experiment of the model compound 2-methylnaphthalene, catalyst showed a good hydrogenation effect, and it is proved that there is the best catalytic effect at the reaction temperature of $415^{\circ} \mathrm{C}$ and the addition amount of $2.5 \mathrm{mg} / \mathrm{g}$. In addition, the catalyst showed noteworthy catalytic effect in coal-oil co-processing reaction

\section{Declarations}

\section{Acknowledgments}


This research was supported by the Fund for Development of Science and Technology of China Coal Research Institute Co. Ltd.(2020CX-II-03)

\section{References}

Hu F, Yan B, Wang G, et al (2019) Technical progress and industrialization status of coal to fuel oil in China. Clean Coal Technology 25:57-63.

Bae J-S, Hwang IS, Kweon Y-J, et al (2012) Economic evaluations of direct, indirect and hybrid coal liquefaction. Korean J Chem Eng 29:868-875.

Han Y, Liu G, Jiang L, et al (2017) Current status and review of clean coal technologies in China. China Mining Magazine 26:81-87+100

Huang C, Li D, Yang T (2016) Status and research trends of co-processing of coal and oil. Modern Chemical Industry 36:8-13.

Huang G, Li D, Qiao M, et al (2020) Development status and industrialization prospect analysis on coal-oil co-refining technology. Petrochemical Technology \& Application 38:1-8

Vasireddy S, Morreale B, Cugini A, et al (2011) Clean liquid fuels from direct coal liquefaction: chemistry, catalysis, technological status and challenges. Energy Environ Sci 4:311-345.

Bellussi G, Rispoli G, Landoni A, et al (2013) Hydroconversion of heavy residues in slurry reactors: developments and perspectives. Journal of Catalysis 308:189-200.

Liu Z (2010) Principal chemistry and chemical engineering challenges in direct coal liquefaction technology. Chemical Industry and Engineering Progress 29:193-197

McMillen DF, Malhotra R, Tse DS (1991) Interactive effects between solvent components: possible chemical origin of synergy in liquefaction and coprocessing. Energy Fuels 5:179-187.

Li W, Li W, Feng J (2020) An overview on issues for lignite direct liquefaction. Journal of China Coal Society $45: 414-423$

Ikenaga N, Sakoda T, Matsui T, et al (1997) Reactions of coal model compounds in the presence of hydrogen donor solvents and highly dispersed catalysts. Energy Fuels 11:183-189.

Bodman SD, McWhinnie WR, Begon V, et al (2002) Metal-ion pillared clays as hydrocracking catalysts (I): catalyst preparation and assessment of performance at short contact times. Fuel 81:449-459.

Chianelli RR, Berhault G, Torres B (2009) Unsupported transition metal sulfide catalysts: 100 years of science and application. Catalysis Today 147:275-286. 
Nikulshin PA, Salnikov VA, Mozhaev AV, et al (2014) Relationship between active phase morphology and catalytic properties of the carbon-alumina-supported $\mathrm{Co}(\mathrm{Ni}) \mathrm{Mo}$ catalysts in HDS and HYD reactions. Journal of Catalysis 309:386-396.

Li C, Meng H, Yang T, et al (2018) Study on catalytic performance of oil-soluble iron-nickel bimetallic catalyst in coal/oil co-processing. Fuel 219:30-36.

Chen Z, Xie J, Liu Q, et al (2019) Characterization of direct coal liquefaction catalysts by their sulfidation behavior and tetralin dehydrogenation activity. Journal of the Energy Institute 92:1213-1222.

Kuznetsov PN, Kuznetsova LI, Chumakov VG, et al (2000) Mechanochemical activation of iron ore-based catalysts for the hydrogenation of brown coal. Materials Research Innovations 3:340-346.

Kaneko T, Sugita S, Tamura M, et al (2002) Highly active limonite catalysts for direct coal liquefaction. Fuel 81:1541-1549.

Sheng J, Baikenov MI, Liang X, et al (2017) Rapid separation and large-scale synthesis of $\beta-\mathrm{FeOOH}$ nanospindles for direct coal liquefaction. Fuel Processing Technology 165:80-86.

Zhou X, Ma F, Liu J, et al (2018) Effect of coated $\mathrm{Fe}_{2} \mathrm{O}_{3}$ nanocatalysts on direct liquefaction of lower-rank coal. Journal of China Coal Society 43:2895-2902

Xie J, Lu H, Shu G, et al (2018) The relationship between the microstructures and catalytic behaviors of iron-oxygen precursors during direct coal liquefaction. Chinese Journal of Catalysis 39:857-866.

Lokhat D, Carsky M (2019) Direct coal liquefaction using iron carbonyl powder catalyst. Chem Eng Technol 42:818-826.

Wang X, Li Y, Liu B, et al (2020) $\mathrm{Fe}_{3} \mathrm{O}_{4}$ nanoparticles supported on modified coal toward catalytic hydrogenation of coal to oil. ACS Omega 5:16789-16795.

Panariti N, Bianco AD, Piero GD, Marchionna M (2000) Petroleum residue upgrading with dispersed catalysts Part 1. catalysts activity and selectivity. Applied Catalysis A: General 204:203-213.

Du H, Li M, Liu D, et al (2015) Slurry-phase hydrocracking of heavy oil and model reactant: effect of dispersed Mo catalyst. Appl Petrochem Res 5:89-98.

Kim K-D, Lee Y-K (2019) Active phase of dispersed MoS2 catalysts for slurry phase hydrocracking of vacuum residue. Journal of Catalysis 369:111-121.

Kang KH, Kim GT, Park S, et al (2019) A review on the Mo-precursors for catalytic hydroconversion of heavy oil. Journal of Industrial and Engineering Chemistry 76:1-16. 
Chianelli RR, Siadati MH, De la Rosa MP, et al (2006) Catalytic properties of single layers of transition metal sulfide catalytic materials. Catalysis Reviews 48:1-41.

Liu B, Zhao K, Chai Y, et al (2019) Slurry phase hydrocracking of vacuum residue in the presence of presulfided oil-soluble MoS2 catalyst. Fuel 246:133-140.

Nguyen MT, Nguyen NT, Cho J, et al (2016) A review on the oil-soluble dispersed catalyst for slurry-phase hydrocracking of heavy oil. Journal of Industrial and Engineering Chemistry 43:1-12.

Xu J, Che X, Wang J (2018) Research progress of the oil-soluble catalyst for slurry-bed hydrocracking of heavy oil. Contemporary Chemical Industry 47:1045-1048.

Yu Q, Li R, Tian H, et al (2021) Research progress on oil-soluble catalysts for slurry-bed hydrogenation of residual oil. Modern Chemical Industry 41:34-37.

Ortiz-Moreno H, Ramírez J, Sanchez-Minero F, et al (2014) Hydrocracking of Maya crude oil in a slurryphase batch reactor. II. Effect of catalyst load. Fuel 130:263-272.

Nguyen TS, Tayakout-Fayolle M, Lacroix M, et al (2015) Promotion effects with dispersed catalysts for residue slurry hydroconversion. Fuel 160:50-56.

Wang T, Hou H, Dong M, et al (2020) Research progress on oil-soluble catalysts precursor for slurry-phase hydrocracking of residue. Chemical Industry and Engineering Progress 39:3669-3676.

Daage M, Chianelli RR (1994) Structure-Function Relations in Molybdenum Sulfide Catalysts: The "RimEdge" Model. Journal of Catalysis 149:414-427.

Taunton JW, Trachte KL, Williams RD (1981) Coal feed flexibility in the Exxon Donor Solvent coal liquefaction process. Fuel 60:788-794.

\section{Figures}



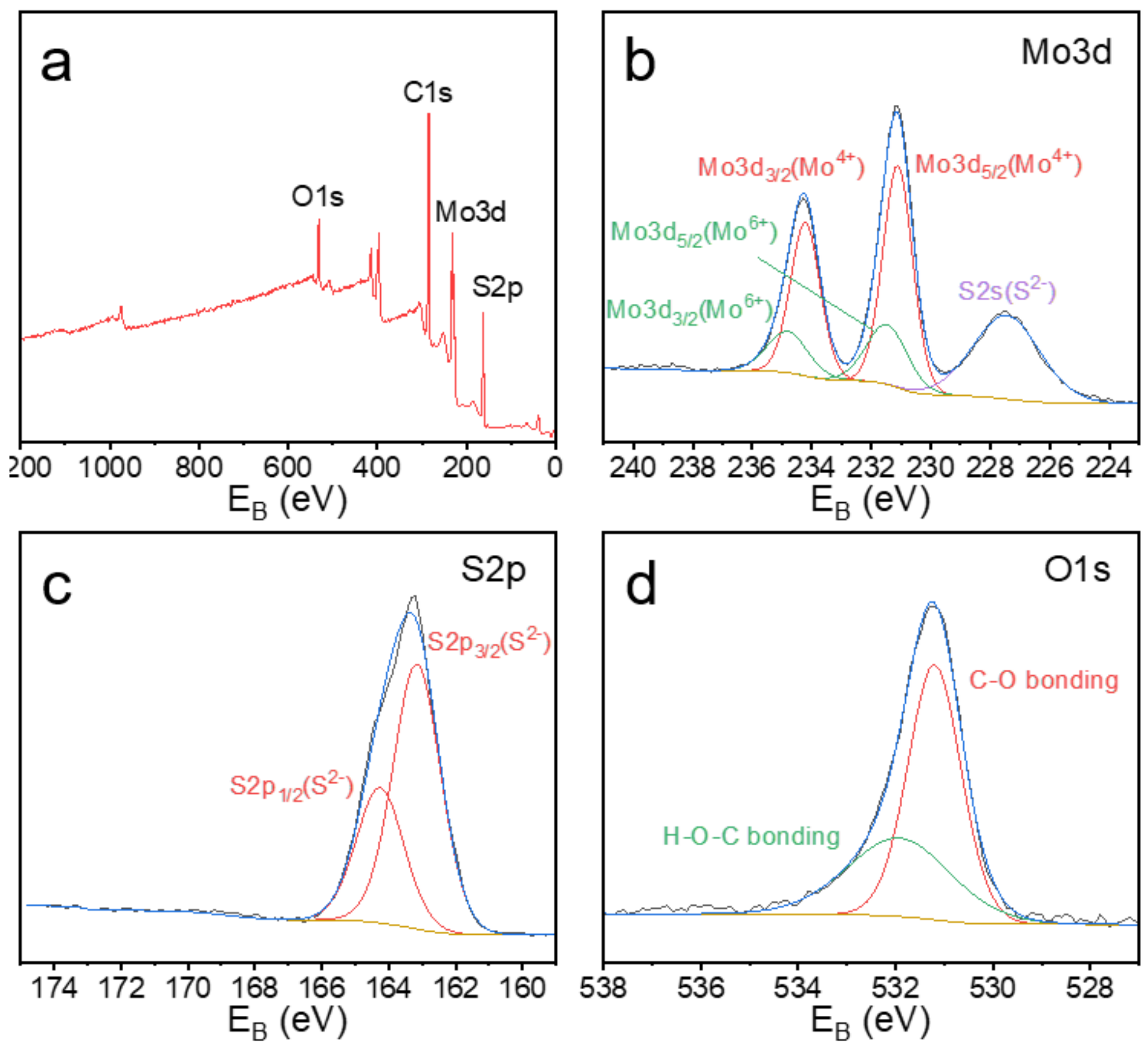

Figure 1

XPS patterns of catalyst precursor. 

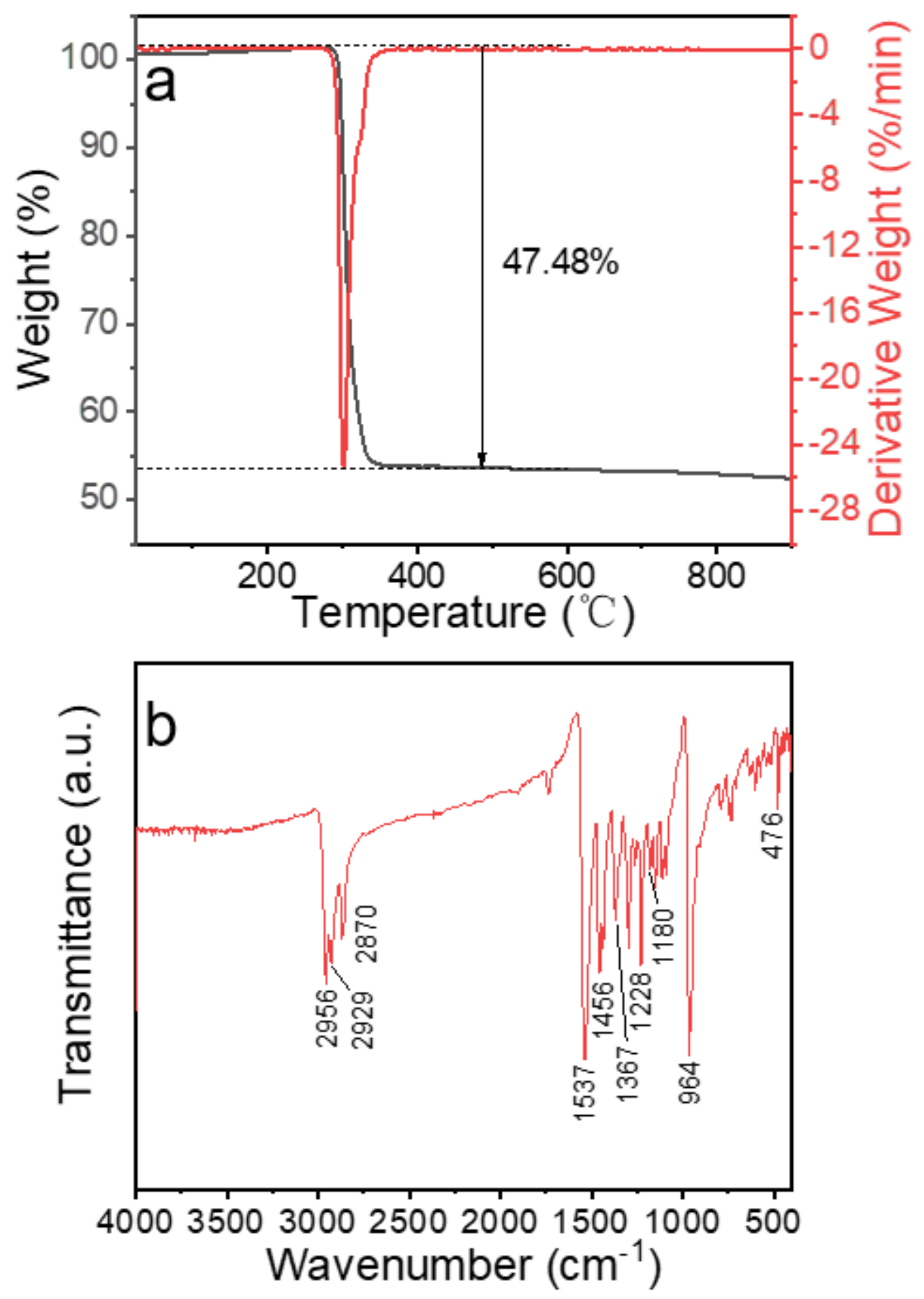

Figure 2

(a) TG curve (black line) and DTG curve (red line) of catalyst precursor. (b) FT-IR spectrum of catalyst precursor. 

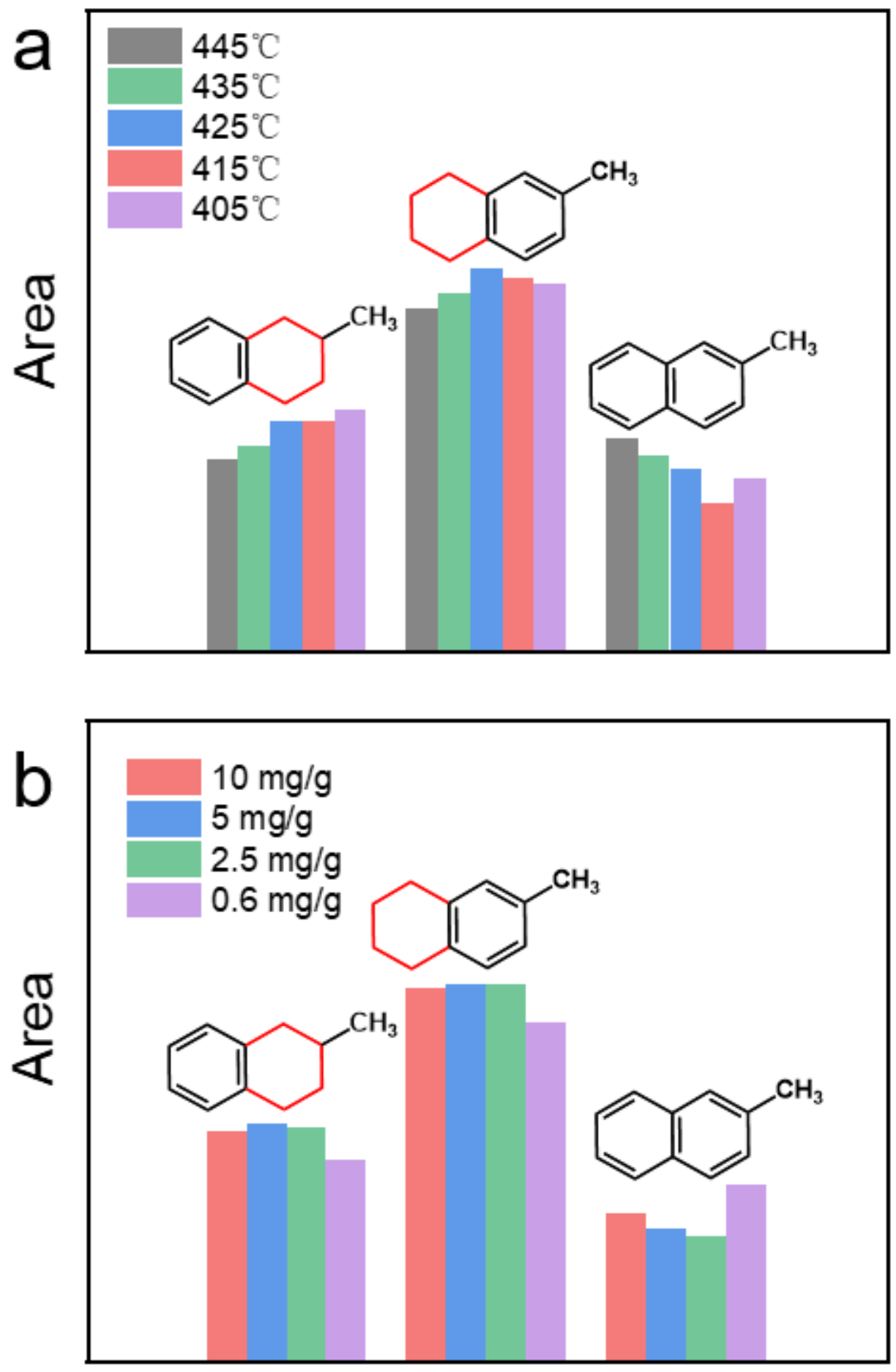

Figure 3

GC-MS spectra of 2-methylnaphthalene and its two hydrogenated products: (a) different reaction temperature; (b) different catalyst concentration. 

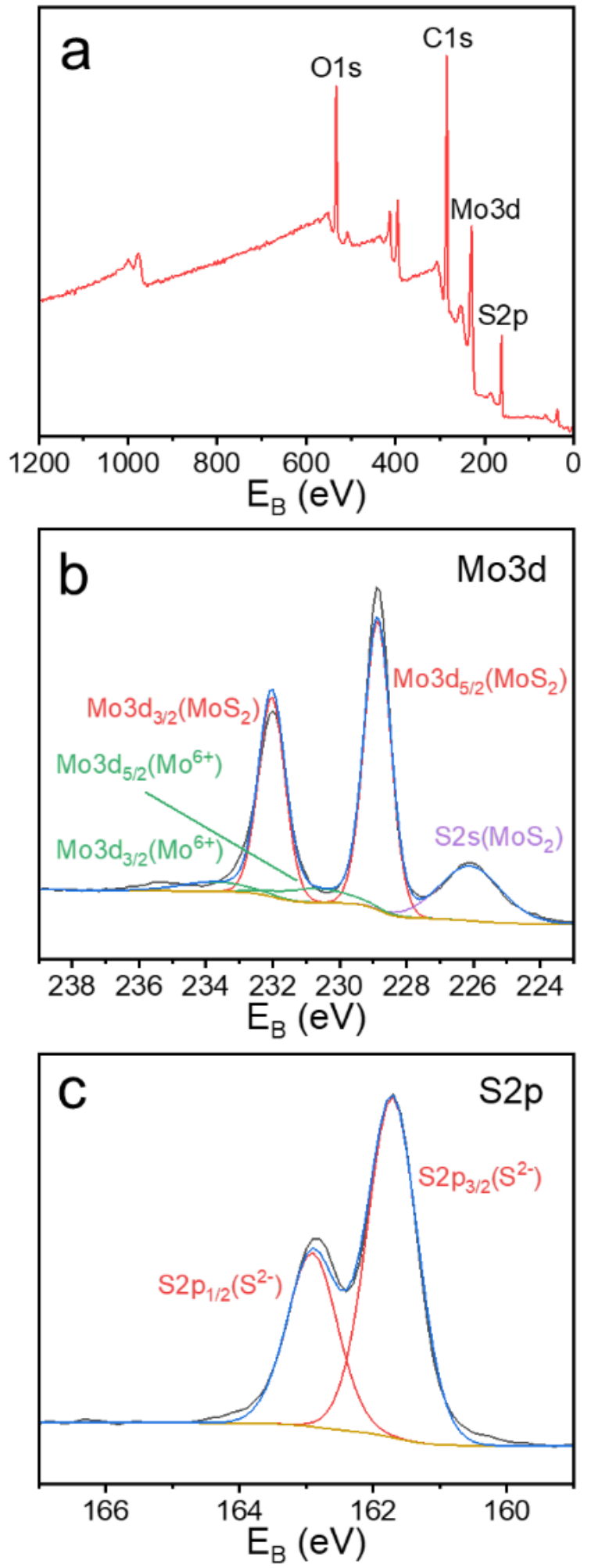

Figure 4

XPS spectra of solid product. 


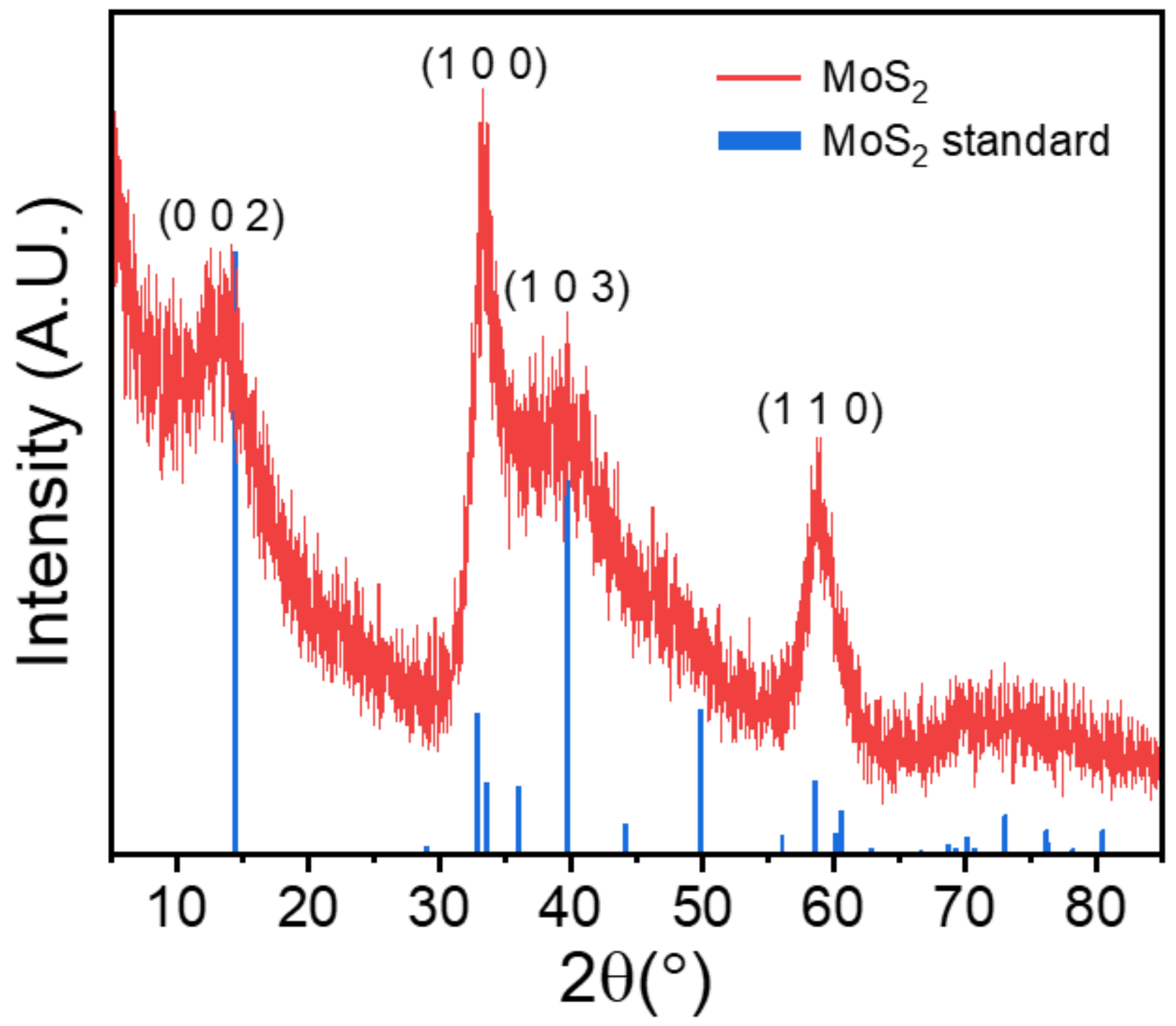

Figure 5

XRD pattern of particles in solid product of hydrocracking reaction. 


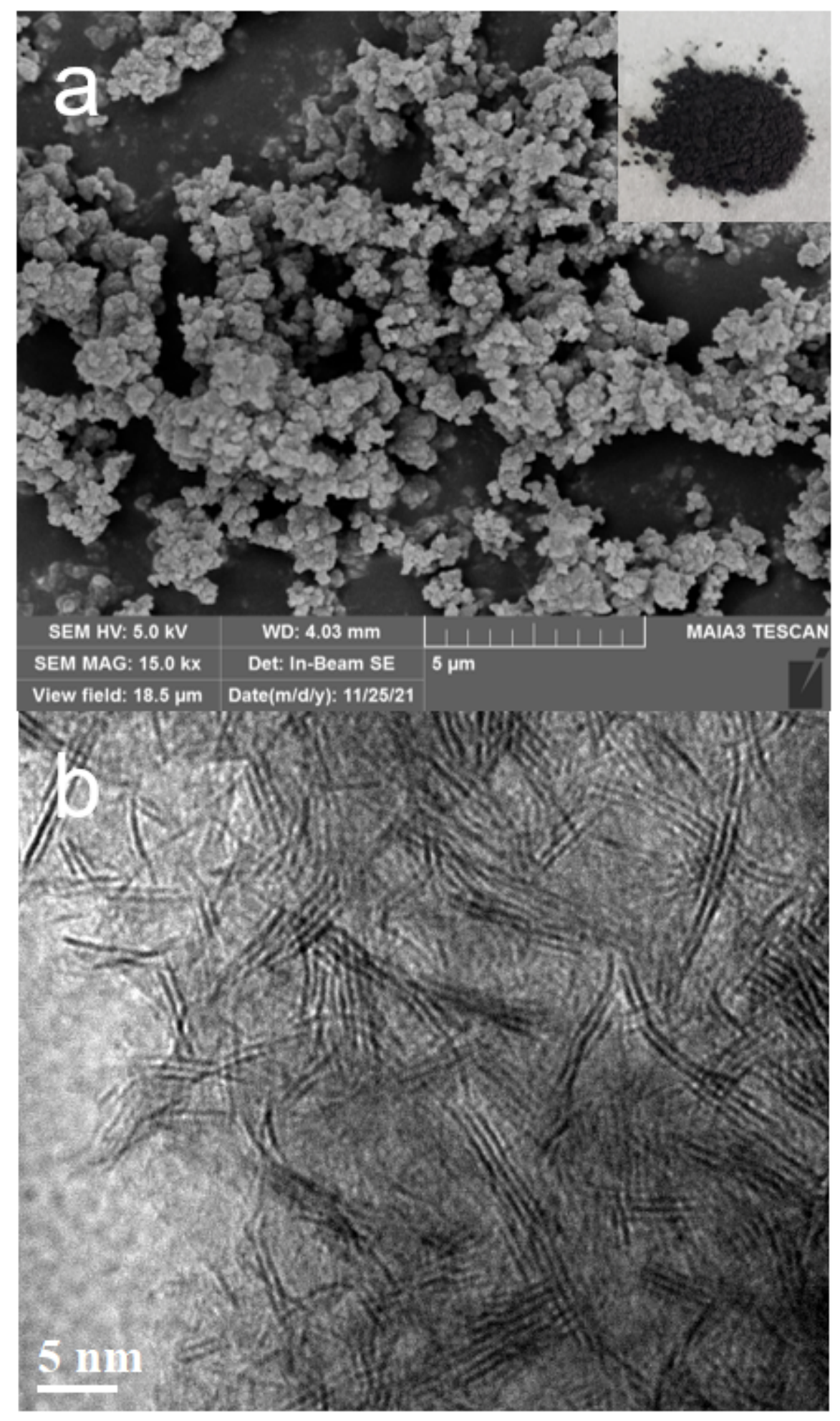

Figure 6

(a) SEM image and (b) HRTEM image of $\mathrm{MoS}_{2}$ catalyst. The illustration is photograph of solid product. 

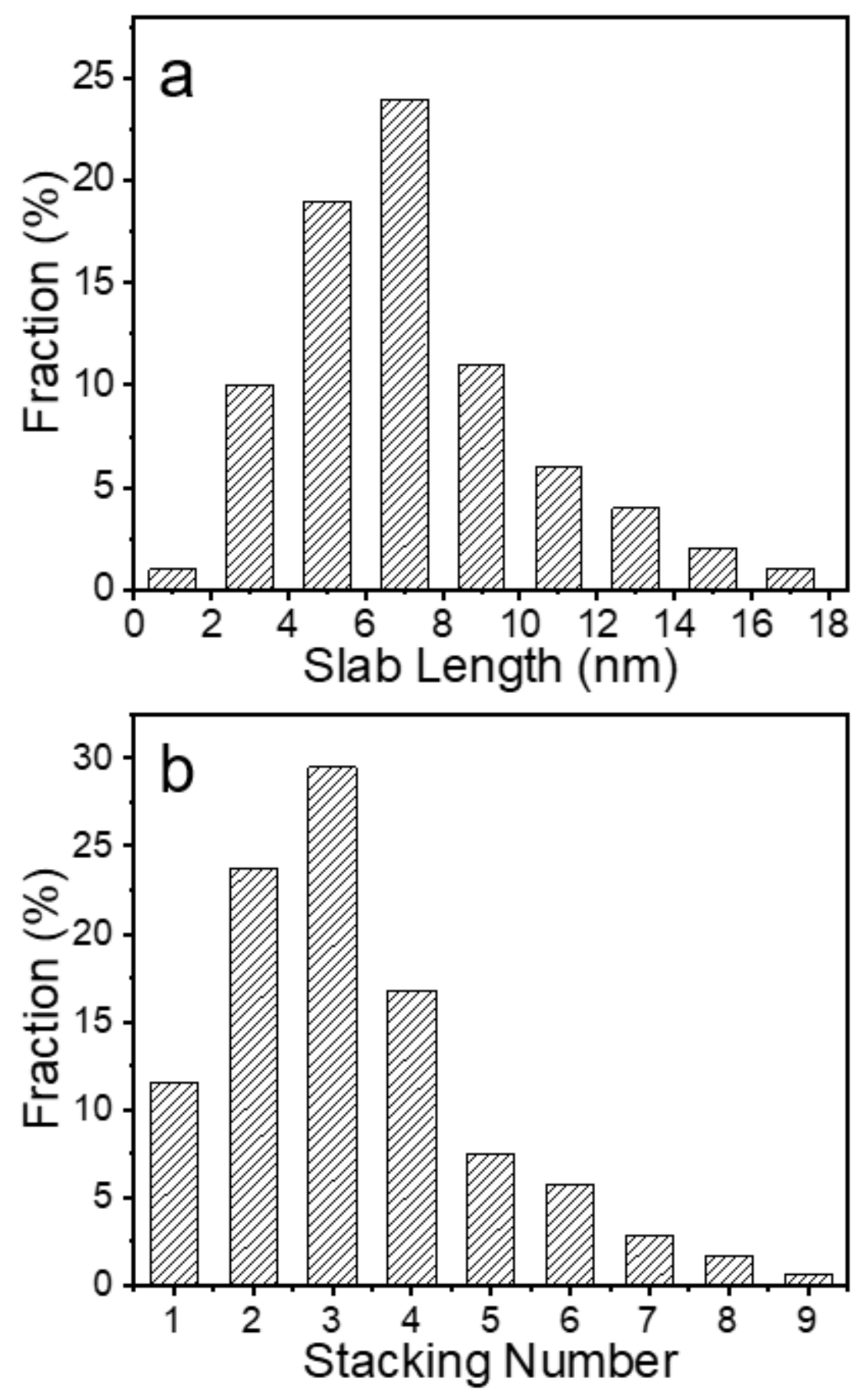

Figure 7

Distributions of slab length (a) and stacking number (b) of $\mathrm{MoS}_{2}$ particles of liquid product. 

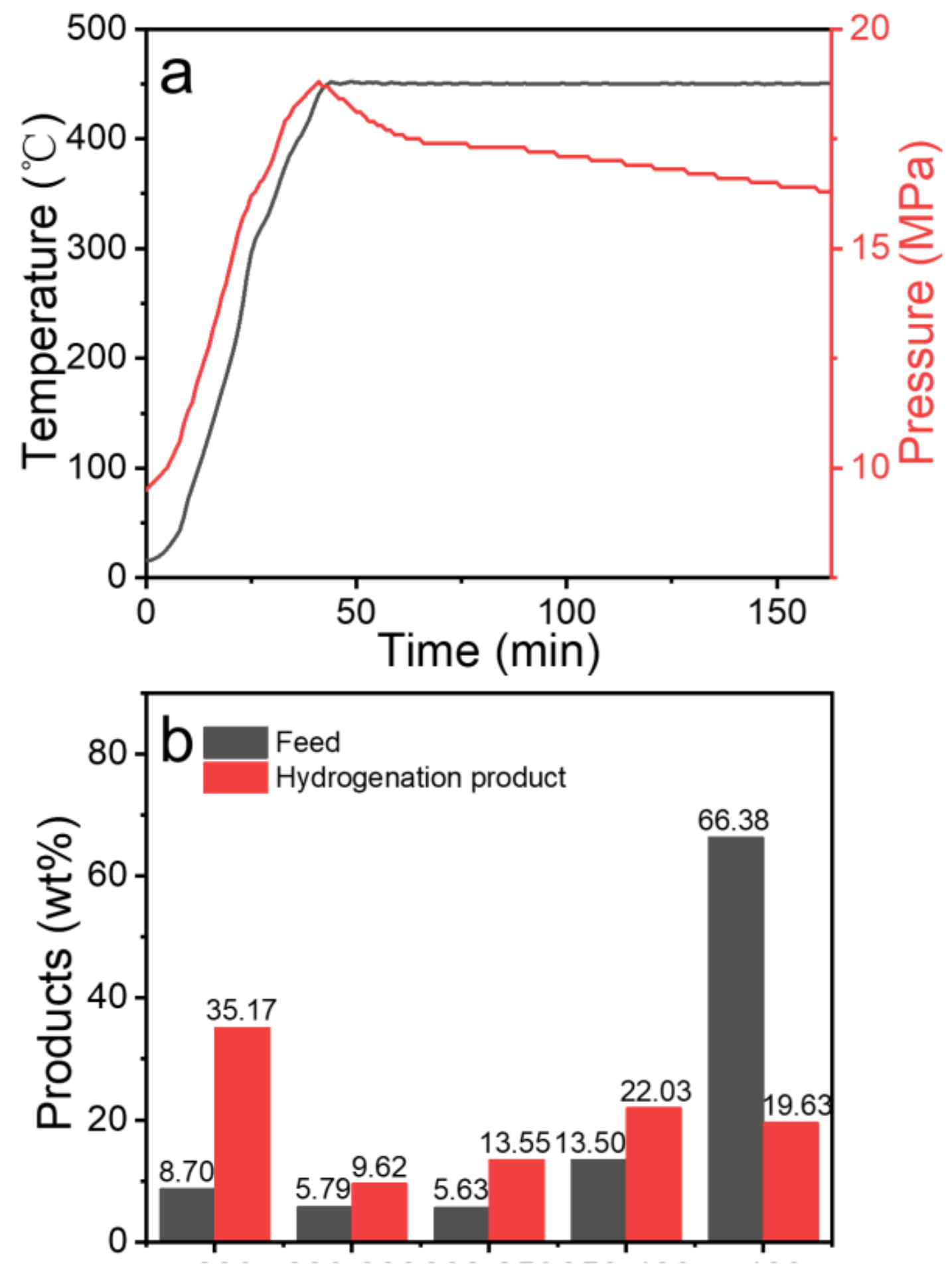

Figure 8

(a) Temperature and pressure of coal-oil co-processing reactions; (b) Different distillate fractions in liquid products of coal-oil co-processing. 


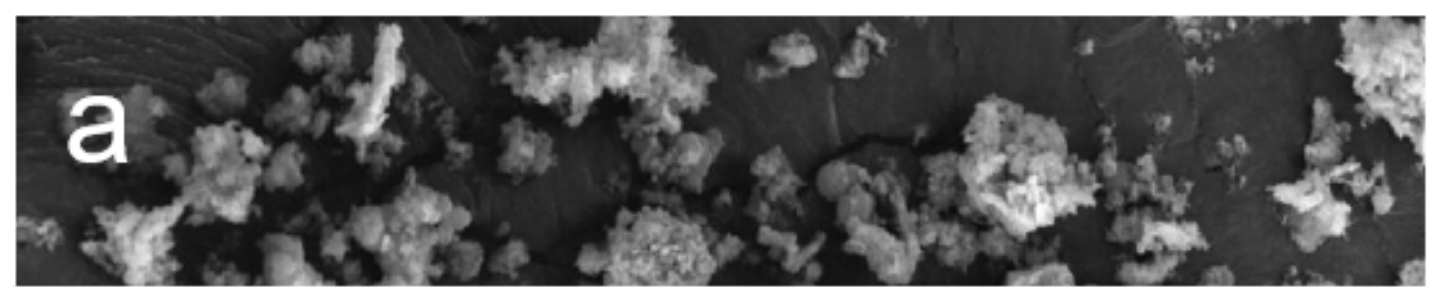

Figure 9

SEM image images of solid product of coal-oil co-processing reactions.

\section{Supplementary Files}

This is a list of supplementary files associated with this preprint. Click to download. 
- Supportinginformation20211229.docx 